\title{
Does the School Financing Role Matter in E-Learning Adoption? An Explanatory Sequential Study in Midwifery Schools in Uganda
}

\author{
June Patrick Bigirwa \\ Department of Educational Planning \&Management, Kyambogo University, Kampala, Uganda \\ ORCID: 0000-0003-0215-9632 \\ Stephen Ndawula \\ Department of Educational Planning \&Management, Kyambogo University, Kampala, Uganda \\ ORCID: 0000-0002-1696-6286 \\ Esther Frances Naluwemba \\ Department of Educational Planning \&Management, Kyambogo University, Kampala, Uganda \\ ORCID: 0000-0003-2014-5322
}

Received: 25 Jan 2020

Accepted: 5 Feb 2020

\begin{abstract}
Despite the high level of investment on e-learning programs in Uganda, there is a low adoption of this new pedagogy in midwifery schools. This trend is likely to frustrate government's efforts to improve the skill mix, competencies and numbers of midwives. This research sought to establish whether school financing role was essential to e-learning adoption, and the salient traits of school financing role to be focused on by midwifery schools. An explanatory sequential mixed methods design was employed, ten midwifery schools were sampled with 167 respondents. A moderate positive relationship between school financing role and e-learning adoption $(r=0.402, p=0.000, n=167)$, was ascertained and school financing role accounted for $15.7 \%$ of the variance in e-learning adoption. The salient traits were; diversified sources of funds, deliberate efforts to expand sources of funds, coordination mechanisms for the sources of funds, affordable school fees structure, and a convenient fees payment system. Midwifery schools ought to implement these traits if they are to improve e-learning adoption.
\end{abstract}

Keywords: school financing role, e-learning adoption, midwifery schools, Uganda, developing country

\section{INTRODUCTION}

The early 1970s were characterized by a paradigm shift in education that argued for a move from elite to mass access to higher education globally (Amano \& Kimmonth, 2010; Trow, 2007). As a result, the demand for education, especially in sub Saharan Africa, has more than doubled in the past two decades (Baker, 2014; Lewin, 2009). Bureaucrats and change agents in institutions of higher learning have been grappling with how to manage this rapid change. Amidst this abrupt change, brick and mortar traditional educational systems are becoming more difficult to develop and maintain given the growing demand for higher education (Mbatia, 2008). On the other hand, e-learning has gained popularity and has been positioned as a modern pedagogy aimed at managing this abrupt change (Bates, 2005).

In East Africa and Uganda in particular, e-learning has been positioned as a pedagogy likely to increase the supply of midwives (Amref, 2015). As a result, the e-learning training approach is being used in many health training institutions in Uganda, and particularly by Ministry of Education and Sports (MoES) through the 
Business, Technical, Vocational Education \&Training (BTVET) directorate, to train midwives across twelve midwifery schools (Amref, 2014). However, despite the high level of investment on e-learning program since 2010 , there is a low adoption of this new pedagogy amongst students and faculty in the participating midwifery schools, and those who do start to use the system opt out later (Liao \& Lu, 2008a, 2008b).

This trend of slow e-learning adoption is likely to constrain government's efforts to improve the skill mix, competencies and numbers of midwives in the country. Thus, this research sought to establish whether school financing role was essential to e-learning adoption, and the salient traits of school financing role which ought to be focused on by midwifery schools in order to improve the adoption of e-learning in their respective schools. The two guiding questions were:

i. What is the influence of school financing role on e-learning adoption?

ii. What are the salient traits of school financing role which should be focused on by midwifery schools so as to improve the adoption of e-learning?

The hypothesis advanced was that School financing role improves e-learning adoption.

\section{Financing Role of Health Training Institutions and E-learning Adoption}

The World Health Report of 2006 (WHO, 2006), indicate that health training institutions undertake six key functions: stewardship or institutional governance; provision of educational services; selection and employment of staff members; financing of training; development and maintenance of infrastructure and technology; and generation of information and knowledge. The particular interest of this study is the financing role of midwifery schools, and how they can be enhanced to produce the desired outputs including adoption of innovations to improve their long-term survival (Sirmon \& Hitt, 2003).

There is limited information on the African content and specifically on Uganda on the amounts the country and development agencies invest in pre-service and in-service training of the health workforce. However, it is clear that the level of financing and the way in which it is disbursed to health training institutions have important implications for the size, skills and diversity of the health workforce, and subsequently the adoption of new training innovations such as the e-learning approach (Clark, 1989). In this regard, for any midwifery school to be able to adopt new innovations of training, there is need to ensure adequate levels of financing, fair financing for student access and efficient coordination of sources of funds. To achieve these, there must be deliberate efforts at the institutional management level to figure out how this ought to be accomplished while considering the interests of different stakeholders.

Guo (2006) argues that this calls for an entrepreneurial mind-set of the institutional management. In the financing role of a school, there are three questions that should be answered. What should the institution do to have adequate finances? How can an institution adopt a fair financing strategy for students to be able to access their education through e-learning? How can an institution achieve efficient coordination of its sources of funds? It is evidently clear that answering these questions requires a school to take an entrepreneurial approach to enhance its financial and social value (Guo, 2006).

According to Guo (2014), social entrepreneurship is believed to be one of the categories of entrepreneurship, and hence this creates room for understanding systems and processes that are designed to achieve social change and to generate surplus to support activities that cannot generate revenue (Austin, Stevenson, \& Wei-Skillern, 2012). Social entrepreneurship is critical for generating social impact and assuring financial sustainability. Entrepreneurial orientation with a social focus is a tool that allows the leadership team to proactively strategize to anticipate environmental changes and to lead the social movements that have policy implications (Guo, Liu, \& Lu, 2014).

\section{MATERIALS AND METHODS}

This study used an explanatory sequential mixed methods design to ascertain whether school financing role was relevant to e-learning adoption and the salient school financing role traits to be implemented by 
midwifery schools. An Explanatory Sequential Mixed Methods research design was preferred because of its central premise that a combination of quantitative and qualitative approaches provides a better understanding of a research problem than using a single approach (Creswell, 2013). Quantitative and qualitative approaches of data collection and analysis were employed to generate the findings of the study. In the first phase a structured questionnaire was used to generate stakeholder's views on school financing role and e-learning adoption. Data from the questionnaires was analysed and interpreted and the findings were used to refocus the second phase of data collection and analysis which embraced a qualitative approach by use of key informant interviews and focus group discussions.

\section{Quantitative Phase}

The sample size of the midwifery schools was determined using Morgan and Kreicie technique. After determining the sample size of the schools, simple random sampling was used to select the individual schools to participate in the study. Secondly, the total population of tutors and students from the sampled schools was ascertained, and this was subjected to the Morgan and Kreicie technique to determine a representative sample size of students and tutors to participate in the study. Thirdly, Probability Proportional to Size (PPS) sampling was used to select the proportionate sample size of students and tutors from each of the midwifery schools selected, proportionate to their population. Fourthly, simple random sampling was used to select individual tutors and students to participate in the study from the determined sample size. In total 10 midwifery schools, 98 tutors and 126 students on the e-learning program were sampled to participate in the study.

Quantitative data was analysed by performing both descriptive and inferential analysis. The study used Statistical Package for Social Sciences (SPSS), Version 23 to perform various inferential and descriptive analyses. The inferential analysis was largely focused on correlation and regression analysis of school financing role and e-learning adoption. The Pearson's correlation coefficient was preferred because the data was assumed to be normally distributed and thus aided in measuring the strength of the relationship of variables.

\section{Qualitative Phase}

Three data collection methods for qualitative data were used in this study, these included: key informant interviews, records review and focus group discussions. Qualitative data analysis commenced with commencement of data collection, data was recorded in field notes and supported by audio recorders, transcription was done verbatim and some samples referred back for cross reference. Data was also coded, categorized, and themed. The process of open coding, axial, and selective coding based on Strauss and Corbin (1998) was utilized in data analysis to help in triangulating data and provide a thick and deep description about school financing role and e-learning adoption. Coding procedures also used the comparative sampling method, a technique that allows thick collection of data due to its iterative potential. NVivo software was used in the coding process to aid in the management of the large amount of data and to facilitate the data reduction process.

\section{RESULTS}

A total of two hundred twenty-four (224) questionnaires were distributed and one hundred sixty-seven (167) were completed and returned. The response rate for questionnaires was therefore 74.6 percent. The above response rate was good and offers a reasonable ground to make a case for any recommendations or observations. In addition, a high response rate is desirable in educational research because it shows the enthusiasm of the stakeholders in a particular phenomenon and offers an unbiased estimates (Dillman, 2000; Heberlein \& Baumgartner, 1978). Similarly, according to Mugenda and Mugenda (2003) a response rate of 50 per cent is adequate for analysis and reporting; a rate of 60 per cent is good and a response rate of 70 per cent and above is excellent. The female sample was almost eight time the male sample. 
Table 1. Demographics of respondents $(n=167)$

\begin{tabular}{lcc}
\hline Information & Frequency & Percent (\%) \\
\hline Gender & & 10.8 \\
(1) Male & 18 & 89.2 \\
(2) Female & 149 & 49.7 \\
Age & & 29.3 \\
(1) $20-29$ yrs. & 83 & 11.4 \\
(2) $30-39$ yrs. & 49 & 9.6 \\
(3) $40-49$ yrs. & 19 & 4.8 \\
(4) 50 yrs. \&above & 16 & 29.3 \\
Highest education level & & 3.6 \\
(1) Post Graduate Diploma & 8 & 62.3 \\
(2) Bachelor's degree & 49 & \\
(3) Master's degree & 6 & 31.7 \\
(4) Certificate & 104 & 54.5 \\
Role of respondent in the school & & 4.8 \\
(1) Tutor & 53 & 9.0 \\
(2) Student & 91 & \\
(3) Administrator & 8 & \\
(4) Clinical instructor & 15 & \\
\hline
\end{tabular}

Based on Table 1, although both male and female respondents participated in the study, the majority 149 $(89.2 \%)$ were females as compared to only $18(10.8 \%)$ males. The females dominated in number because the midwifery profession in Uganda is generally dominated by females both as students and staff. Majority, $79.0 \%$ were below 40 years, depicting a slightly younger population undertaking the e-learning program as either students, tutors or administrators at the sampled midwifery schools. the highest number of respondents, 104 (62.3\%) were of certificate level of education, Respondents who possessed certificates were majorly certificate midwives who had enrolled on the e-learning program to upgrade to the diploma level in midwifery studies, and these constituted the biggest number of respondents as students $54.5 \%$ (91). While respondents with Postgraduate diplomas, Bachelors' and Masters' degrees were either tutors or administrators. The above findings are an indication that all stakeholders on the e-learning program within the midwifery school environment participated in the study.

\section{E-learning Adoption in Midwifery Schools in Uganda}

E-learning adoption was measured on the questionnaire using eight statements to which the respondents were required to indicate their level of agreement or disagreement. The level of e-learning adoption was ascertained to be at $61 \%$ as majority of the respondents somewhat and strongly agreed to all the eight statements used to assess e-learning adoption. However, if only $61 \%$ of students and faculty agree that they are satisfied with the overall e-learning program, and that they are happy with the number of students taking on and using e-learning as their main approach for their quest for knowledge and skills, quantitatively expressed in terms of number of students enrolled on the program; number of students and tutors using LMS/CD-ROM; and the number of faculty offering online support to their learners, the $40 \%$ who superficially pronounce disaffection represents a slightly bigger constituency of likely defaulters over time, and something needs to be done to arrest the situation.

\section{Views of Participants on School Financing Role}

In order to understand the views of the respondents on school financing role, so as to analyse whether it has a contribution to e-learning adoption in midwifery schools in Uganda, the study used six (6) statements on the questionnaire to which the respondents were required to show their level of agreement or disagreement and the findings are presented in Table 2. Qualitative findings collected from interview guides, FGDs and document reviews were used to supplement the quantitative findings. 
Table 2. Views of participants on school financing role

\begin{tabular}{|c|c|c|c|c|c|c|}
\hline \multicolumn{2}{|c|}{ Statements } & \multirow{2}{*}{$\frac{S D}{31(18.6)}$} & \multirow{2}{*}{$\frac{\text { SWD }}{29(17.4)}$} & \multirow{2}{*}{$\frac{\text { NAD }}{41(24.6)}$} & \multirow{2}{*}{$\begin{array}{c}\text { SWA } \\
57(34.1)\end{array}$} & \multirow{2}{*}{$\frac{\text { SA }}{9(5.4)}$} \\
\hline 1) & Our school has diversified sources of funds & & & & & \\
\hline 2) & $\begin{array}{l}\text { In our school, there are deliberate efforts for expanding } \\
\text { sources of funds. }\end{array}$ & $30(18.0)$ & $28(16.8)$ & $41(24.6)$ & $54(32.3)$ & $14(8.4)$ \\
\hline 3) & $\begin{array}{l}\text { At our school, there is good coordination mechanisms for } \\
\text { our sources of funds }\end{array}$ & $32(19.2)$ & $32(19.2)$ & $42(25.1)$ & $49(29.3)$ & $12(7.2)$ \\
\hline 4) & $\begin{array}{l}\text { At our school there is a good school fees structure relevant } \\
\text { to each study program }\end{array}$ & $27(16.2)$ & $35(21.0)$ & $17(10.2)$ & $48(28.7)$ & $40(24.0)$ \\
\hline 5) & $\begin{array}{l}\text { The school fees structure for e-learning program is } \\
\text { affordable }\end{array}$ & $38(22.8)$ & $37(22.2)$ & $25(15.0)$ & $40(24.0)$ & $27(16.2)$ \\
\hline 6) & $\begin{array}{l}\text { The school fees payment system for e-learning program is } \\
\text { convenient }\end{array}$ & $25(15.0)$ & $35(21.0)$ & $44(26.3)$ & $52(31.1)$ & $11(6.6)$ \\
\hline Ave & rage of School financing role & $10(6.0)$ & $36(21.6)$ & $67(40.1)$ & $46(27.5)$ & $8(4.8)$ \\
\hline
\end{tabular}
Key: SD: Strongly Disagree, SWD: Somewhat Disagree, NAD: Neither Agree nor Disagree, SWA: Somewhat Agree, SA: Strongly Agree

Table 2 shows that respondents were in agreement on only one (1) out of the six (6) statements used to measure school financing role in midwifery schools in Uganda as detailed; on whether at the school there is a good school fees structure relevant to each study program, $28.7 \%$ somewhat agreed and $24.0 \%$ strongly agreed. This means that the majority, $52.7 \%$ were of the view that there is a good school fees structure relevant to each study program in their schools. In line with the above quantitative findings a key informant when asked how convenient the school fees payment system is for e-learning program, she said;

"The fees payment system is very friendly; students first pay a deposit then pay as and when they get some money up to the time of examinations".

A $3^{\text {rd }}$ year diploma in midwifery e-learning student added as thus;

"The school fees structure is quite relevant and convenient to us since we're allowed to pay in instalments".

Table 2 further shows that the majority of the respondents had mixed reactions on five (5) out of the six (6) statements used to measure school financing role in midwifery schools in Uganda as detailed; on whether schools have diversified sources of funds, $18.6 \%$ strongly disagreed, whereas $17.4 \%$ somewhat disagreed, $24.6 \%$ neither agreed or disagreed, while $34.1 \%$ somewhat agreed and $5.4 \%$ strongly agreed. This suggests that there were mixed reactions on whether schools have diversified sources of funds, with $36.0 \%$ in disagreements, $24.6 \%$ neither in agreement nor in disagreed and $39.5 \%$ in agreement. The major sources of funds for the schools include government conditional grants, school fees and tuition. A key informant explained that these sources of funds are not sufficient for the day today running of the institutions.

In respect to whether there are deliberate efforts for expanding sources of funds in the schools, $18.0 \%$ strongly disagreed, whereas $16.8 \%$ somewhat disagreed, $24.6 \%$ neither agreed nor disagreed, while $32.3 \%$ somewhat agreed and $8.4 \%$ strongly disagreed. This implies that there were mixed reactions on whether there are deliberate efforts for expanding sources of funds in the schools, with $34.8 \%$ in disagreement, $24.6 \%$ neither in agreement nor in disagreement and $40.7 \%$ in agreement. Asked further whether there is good coordination mechanisms for sources of funds in the schools, $19.2 \%$ strongly disagreed, whereas a similar number somewhat disagreed, $25.1 \%$ neither agreed nor disagreed, while $29.3 \%$ somewhat agreed and $7.2 \%$ strongly agreed. This suggests that there were mixed reactions on whether there is good coordination mechanisms for sources of funds in the schools, with 38.4\% in disagreement, 25.1 neither in agreement nor in disagreement and $36.5 \%$ in agreement. A key informant explained that although they would have liked to expand the sources of funds in the schools, they have a lot of limitations because the schools do not have authority to expand school fees without approval from government.

On whether the school fees structure for e-learning program is affordable, $22.8 \%$ strongly disagreed, whereas $22.2 \%$ somewhat agreed, $15.0 \%$ neither agreed nor disagreed, while $24.0 \%$ somewhat agreed and $16.2 \%$ 
Table 3. Correlation matrix for school financing role and e-learning adoption

\begin{tabular}{lccc}
\hline & & School financing role & E-learning adoption \\
\hline School financing role & Pearson Correlation & 1 & $.402^{*}$ \\
& Sig. (2-tailed) & & .000 \\
E-learning adoption & $\mathrm{N}$ & 167 & 167 \\
& Pearson Correlation & $.402^{*}$ & 1 \\
& Sig. (2-tailed) & .000 & 167 \\
\hline
\end{tabular}

*. Correlation is significant at the 0.05 level (2-tailed)

strongly agreed. This means that there were mixed reactions on whether the school fees structure for elearning program is affordable, with $45.0 \%$ in agreement, $15.0 \%$ neither in agreement nor in disagreement and $40.2 \%$ in agreement. Furthermore, on whether the school fees payment system for e-learning program is convenient, $15.0 \%$ strongly disagreed, whereas $21.0 \%$ somewhat agreed, $26.3 \%$ neither agreed nor disagreed, while $31.1 \%$ somewhat agreed and $6.6 \%$ strongly agreed. This suggests that there were mixed reactions on whether the school fees payment system for e-learning program is convenient, with $36.0 \%$ in disagreed, $26.3 \%$ neither in agreement nor in disagreement and $37.7 \%$ in agreement. During a FGD participants noted that although the school fees payment system appears to be convenient because of being able to pay in instalments, the actual fees is rather high. For instance, in one of the Midwifery schools, elearning students are required to pay $\$ 550$ per semester whereas the full-time students are required to pay $\$ 770$. One of the FGD participants explained;

\footnotetext{
"The fees for e-learning is quite high especially when you're not being sponsored by your employers. The situation is even more complicated given the fact that you have to meet transport and accommodation expenses, procurement of a laptop and internet access fees".
}

\section{Average of School Financing Role}

On average $6.0 \%$ of the respondents strongly disagreed to all the statements used to measure school financing role, whereas $21.6 \%$ somewhat disagreed, $40.1 \%$ neither agreed nor disagreed, $27.5 \%$ somewhat agreed and $4.8 \%$ strongly agreed. This is an indication that generally the respondents had mixed reactions to all the statements used to measure school financing role in midwifery schools in Uganda, with on average $27.6 \%$ in disagreement, $40.1 \%$ neither in agreement nor in disagreement and $32.3 \%$ in agreement.

\section{Correlation Analysis for School Financing Role and E-learning Adoption}

In order to assess whether there is a relationship between school financing role and e-learning adoption in midwifery schools in Uganda, Pearson's product-moment correlation coefficient was generated at 95\% confidence level to compute the degree and direction of the relationship between the two variables and the results are presented in Table 3.

Table 3 shows that there is a moderate positive relationship between school financing role and e-learning adoption in midwifery schools in Uganda, $(r=0.402, p=0.000, n=167)$. The relationship is statistically significant at $95 \%$ confidence level since $p$-value (Sig.) equal $0.000(<0.050)$. This means that improvements in school financing role shall be related to improvements in e-learning adoption in midwifery schools in Uganda. Similarly decline in school financing role shall be related to decline in e-learning adoption in midwifery schools in Uganda.

\section{Regression Analysis for School Financing Role and E-learning Adoption}

Regression analysis was used to analyse whether school financing role has a significant contribution to elearning adoption in midwifery schools in Uganda. The coefficient of determination ( $R$ Square) under regression analysis is presented in Table 4. 
Table 4. Model Summary of regression analysis for school financing role and e-learning adoption

\begin{tabular}{lccc}
\hline Model & $\mathrm{R}$ & $\mathrm{R}$ Square & Adjusted R Square \\
\hline 1 & $.402^{\mathrm{a}}$ & .162 & .157 \\
\hline
\end{tabular}

a. Predictors: (Constant), School financing role

Table 5. ANOVA and regression coefficients for school financing role and e-learning adoption

\begin{tabular}{lcccccc}
\hline & \multicolumn{3}{c}{ ANOVA } & \multicolumn{3}{c}{ Coefficients } \\
\hline Model & Df & F & Sig. & Standardized Beta Coefficient & T & Sign \\
Regression & 1 & 31.869 & $0.000^{\mathrm{a}}$ & 0.402 & 5.645 & $0.000^{\mathrm{b}}$ \\
\hline
\end{tabular}

a. Dependent Variable: E-learning adoption

b. Predictors: (Constant), School financing role

Table 4 shows Pearson's correlation coefficient $(R=0.402)$, Coefficient of determination or $R$ Square of 0.162 and Adjusted $R$ Square of 0.157. An adjusted $R$ Square of 0.157 means that school financing role accounts for $15.7 \%$ of the variance in e-learning adoption in midwifery schools in Uganda. This means that apart from school financing role there are other factors that contribute to e-learning adoption in midwifery schools in Uganda.

To assess the overall significance of the regression model for school financing role and e-learning adoption in midwifery schools in Uganda, Analysis of Variance (ANOVA) and regression coefficients were generated, and the results are presented in Table 5.

In determining whether a regression model is significant, the decision rule is that the calculated p-value (level of significance) for ANOVA must be less than or equal to 0.05 . Since the calculated $p$-value of $0.000^{\mathrm{a}}$ is less than 0.05 , the regression model was found to be statistically significant $(F=31.869, d f=1, p<0.05(=0.000)$ ). This means that school financing role has a statistically significant contribution to e-learning adoption in midwifery schools in Uganda.

Furthermore, to establish whether school financing role is a predictor of e-learning adoption in midwifery schools in Uganda and determine the magnitude to which school financing role contributes to e-learning adoption in midwifery schools in Uganda, Standardized Beta and t Coefficients were generated. For the magnitude to be significant the decision rule is that the $t$ value must not be close to 0 and the $p$-value must be less than or equal to 0.05 . Since the $t-$ value of 5.645 is not close to 0 and $p$-value $<0.05(=0.000)$, the study confirmed that school financing role is a predictor of e-learning adoption in midwifery schools in Uganda. A standardized Beta coefficient of 0.402 means; every 1 unit increase in school financing role will lead to an increase of 0.402 units of e-learning adoption in midwifery schools in Uganda.

Research findings from correlation analysis established that school financing role has a moderate positive statistically significant relationship with e-learning adoption in midwifery schools in Uganda. Findings from regression analysis confirmed that school financing role has a statistically significant positive contribution to e-learning adoption in midwifery schools in Uganda. The study therefore accepted the research hypothesis that was stated as thus: School financing role improves e-learning adoption.

\section{Salient Traits of School Financing Role and Ways of Improving Them}

The major salient traits of school financing role were found to be: diversified sources of funds, deliberate efforts to expand sources of funds, coordination of mechanisms for the sources of funds, favourable schools fees structure for each study program, affordable school fees structure for e-learning program and a convenient fees payment system for e-learning program. Most if these traits were found to be insufficiently implemented at the school level, yet deliberate efforts of focusing on them can greatly improve new learning innovations including the e-learning pedagogy (WHO, 2006).

Diversified sources of funds for a midwifery school can provide opportunities for implementing new learning innovations such as e-learning. Favourable, affordable and convenient school fees structure and payment system can motivate the learners to be able to pay for their school dues, additionally visualising e-learning 
as a cost effective future business prospects can allow midwifery school administrators to invest in hard and software e-learning infrastructure with aim of achieving cost reductions on major cost centres of learning. All these deliberate efforts can greatly enhance the adoption of e-learning in the long run.

\section{DISCUSSION}

The major research findings established that school financing role has a moderate positive statistically significant relationship with e-learning adoption in midwifery schools in Uganda and furthermore it was established that school financing role has a statistically significant positive contribution to e-learning adoption in midwifery schools in Uganda. These findings are in agreement with (Clark, 1989) that found out that the level of financing and the way in which it is disbursed to health training institutions have important implications for the size, skills and diversity of the health workforce, and subsequently the adoption of new training innovations such as the e-learning approach. This was further collaborated by research findings that revealed that there is a good school fees structure that is relevant to each study program in their schools.

According to Guo (2006), for any nursing and midwifery school to be able to adopt new innovations of training, there is need to ensure adequate levels of financing, fair financing for student access and efficient coordination of sources of funds. To achieve these, Guo (2006) argues that there must be deliberate efforts at the institutional management level to figure out how this ought to be accomplished while considering the interests of different stakeholders. However, research findings revealed that there were mixed reactions on whether schools have diversified sources of funds and whether there are deliberate efforts for expanding sources of funds in the schools. This implies that most of the nursing and midwifery schools have gaps in funding and do not have very clear deliberate efforts towards expansion of sources of funds in their schools. According to Guo (2014), social entrepreneurship is believed to be one of the categories of entrepreneurship, and hence it creates room for understanding systems and processes that are designed to achieve social change and to generate surplus to support activities that cannot generate revenue (Austin et al., 2012). However, social entrepreneurship may not be practical in most of the schools because most of them have a lot of limitations because they do not have authority to expand school fees without approval from government. This means that they must continue relying on the limited funding from government and the little tuition that students pay to pursue their courses. Therefore, although social entrepreneurship is critical for generating social impact and assuring financial sustainability, it is currently not one of the options that the schools can use to finance their activities.

\section{CONCLUSION}

Based on the research findings it is concluded that improvements in the school financing role shall lead to improvements in adoption of e-learning in midwifery schools in Uganda. However, under the current status the following recommendations are here under made to ensure that school financing roles contribute to adoption of e-learning; the current school fees structure should be upheld since it is relevant to each study program in the schools. It should however be adjusted to be affordable to most of the students. Midwifery schools should diversify their sources of funds and make deliberate efforts for expanding sources of funds. Midwifery schools should improve on the coordination mechanisms for sources of funds. The current school fees payment system for e-learning program should be improved upon or other payment systems should be introduced for the convenience of all students.

\section{REFERENCES}

Amano, I., \& Kimmonth, E. H. (2010). Structural changes in the higher education system in Japan: Reflections on the comparative study of higher education using the theory of Martin Trow. Educational Studies in Japan, 5, 79-93. https://doi.org/10.7571/esjkyoiku.5.79

Amref. (2014). The Uganda eLearning Midwives Upgrading Project Annual Report (October 2013-September 2014). Amref Health Africa in Uganda 
Amref. (2015). E learning program improves midwifery skills- Ketty's story. Retrieved from https://amref.org/uganda/success-stories/e-learning-program-improves-midwifery-skills-kettysstory/

Austin, J., Stevenson, H., \& Wei-Skillern, J. (2012). Social and commercial entrepreneurship: same, different, or both? Revista de Administração (São Paulo), 47(3), 370-384. https://doi.org/10.5700/rausp1055

Baker, D. (2014). The schooled society: The educational transformation of global culture. Palo Alto, CA, USA: Stanford University Press.

Bates, A. T. (2005). Technology, e-learning and distance education. London: Routledge. https://doi.org/10.4324/9780203463772

Clark, K. B. (1989). What strategy can do for technology. The five rules of technology leadership. Harvard Business Review, 67(6), 94.

Creswell, J. W. (2013). Research design: Qualitative, quantitative, and mixed methods approaches. Thousand Oaks, CA, USA: Sage publications.

Dillman, D. A. (2000). Procedures for conducting government-sponsored establishment surveys: Comparisons of the total design method (TDM), a traditional cost-compensation model, and tailored design. Paper presented at the Proceedings of American Statistical Association, Second International Conference on Establishment Surveys.

Guo, K. L. (2006). Entrepreneurship management in health services: An integrative model. Journal of Health and Human Services Administration, 28(4), 504-530.

Guo, K. L., Liu, S. S., \& Lu, J.-f. R. (2014). Using a Social Entrepreneurial Approach to Enhance the Financial and Social Value of Health Care Organizations.

Heberlein, T. A., \& Baumgartner, R. (1978). Factors affecting response rates to mailed questionnaires: A quantitative analysis of the published literature. American sociological review, 447-462. https://doi.org/10.2307/2094771

Lewin, K. M. (2009). Access to education in sub-Saharan Africa: patterns, problems and possibilities. Comparative Education, 45(2), 151-174. https://doi.org/10.1080/03050060902920518

Liao, H.-L., \& Lu, H.-P. (2008a). Richness versus parsimony antecedents of technology adoption model for elearning websites. Paper presented at the International Conference on Web-Based Learning.

Liao, H.-L., \& Lu, H.-P. (2008b). The role of experience and innovation characteristics in the adoption and continued use of e-learning websites. Computers \& Education, 51(4), 1405-1416. https://doi.org/10.1016/j.compedu.2007.11.006

Mbatia, P. N. (2008). Education and Information \& Communication Technologies (ICT) inAfrica: Using ICT to improve education in Sub-Saharan Africa. African Journal of sociology, 4(1).

Mugenda, O. M., \& Mugenda, A. (2003). Research methods: Quantitative and: Qualitative Approaches. Nairobi: Acts Press.

Sirmon, D. G., \& Hitt, M. A. (2003). Managing Resources: Linking Unique Resources, Management, and Wealth Creation in Family Firms. Entrepreneurship Theory and Practice, 27(4), 339-358. https://doi.org/10.1111/1540-8520.t01-1-00013

Strauss, A., \& Corbin, J. (1998). Basics of qualitative research: Techniques and procedures for developing grounded theory. Thousand Oaks, CA, USA: Sage publications. 
Trow, M. (2007). Reflections on the transition from elite to mass to universal access: Forms and phases of higher education in modern societies since WWII. International handbook of higher education (pp. 243280). Berlin, Germany: Springer. https://doi.org/10.1007/978-1-4020-4012-2_13

WHO. (2006). The world health report 2006: working together for health. Geneva, Switzerland: World Health Organization.

Correspondence: June Patrick Bigirwa, Department of Educational Planning \&Management, Kyambogo University, Kampala, Uganda. E-mail: bigirwajp@yahoo.com 